\title{
ANALISA PERBAIKAN PRODUKTIVITAS MENGGUNAKAN METODE OVERALL EQUIPMENT EFFECTIVINESS (OEE) PADA MESIN FILLING DENGAN PENDAKATAN SIX BIG LOSSES UNTUK MENCARI PENYEBAB LOSSES TERTINGGI PADA PRODUKSI SKINCARE STUDI KASUS PT XYZ
}

\author{
BAMBANG SUHARDI WALUYO,${ }^{1)}$ CHRISWAHYUDI, ${ }^{2)} \&$ RESTIANINGSIH ${ }^{3)}$ \\ ${ }^{1)}$ Program Studi Teknik Mesin, ${ }^{2,3)}$ Program Studi Teknik Industri \\ Fakultas Sains dan Teknologi, Institut Sains Teknologi Al-Kamal \\ Email: bambang_waluyo07@yahoo.com ${ }^{1)}$
}

\begin{abstract}
PT. XYZ is a cosmetic company whose main objective is to achieve production target which is planned to be fulfilled well. However, due to factors that have the largest percentage of the six big losses factor are reduced speed (34.92\%) and breakdown losses (32.08\%) which can hamper the production process so that the achievement of production targets is still far from expectations. During the period from March to November 2017, the value of OEE (62.54\% $77.83 \%)$, availability ratio $(76.28 \%-85.70 \%)$, performance efficiency $(83.23 \%$ $-99.24 \%)$ and rate quality product (93.11\% -97,09\%). The highest OEE value in September was 77.83\%. And the lowest OEE value in April 2017 (62.54\%). The level of processed capability generated is 0.588 which means that the process capability is low, so it needs to be improved performance through improvement process. Study what conditions can be improved using $5 W+1 H$. What has been done in PT. XYZ is expected to be the first step of increasing the effectiveness of the machine that will arrive at the application of Total Productive Maintenance.

Keywords: Cosmetics, Total Productive Maintenance (TPM), Availability rate, Performance rate, Quality rate, Overall Eqipment Effectiveness, Six Big Losses, $5 \mathrm{WlH}$.
\end{abstract}

\begin{abstract}
ABSTRAK
PT. XYZ merupakan perusahaan yang bergerak di bidang kosmetik yang tujuan utama menginginkan target produksi yang direncanakan dapat terpenuhi dengan baik. Akan tetapi karena faktor yang memiliki persentase terbesar dari faktor six big losses adalah reduce speed (34,92\%) dan breakdown losses $(32,08 \%)$ yang bisa menghambat proses produksi sehingga pencapaian target produksi masih jauh dari harapan. Selama periode Maret- November 2017 di peroleh nilai OEE $(62,54 \%$ - 77,83\%), availability ratio ( 76,28 \% - 85,70\%), performance efficiency $(83,23 \%-99,24 \%)$ dan rate quality product $(93,11 \%-97,09 \%)$. Nilai OEE tertinggi pada bulan September sebesar 77,83 \%. Dan nilai OEE terendah pada bulan April 2017 (62,54 \%). Tingkat kapabilitas yang diproses yang dihasilkan bernilai 0,588 yang bearti bahwa kapabilitas proses rendah, sehingga perlu ditingkatkan performansinya melalui proses perbaikan. Kajian kondisi apa saja yang dapat diperbaiki dengan menggunakan $5 \mathrm{~W}+1 \mathrm{H}$. Apa yang telah dilakukan di PT. XYZ diharapkan dapat menjadi langkah awal peningkatan efektifitas mesin yang nantinya akan sampai pada penerapan Total Productive Maintenance.
\end{abstract}

Kata Kunci: Kosmetik, Total Productive Maintenance (TPM), Availability rate, Performance rate, Quality rate, Overall Eqipment Effectiveness, Six Big Losses, $5 \mathrm{WlH}$ 


\section{PENDAHULUAN}

Pada era industri yang semakin kompetitif ini, setiap perusahaan menginginkan produksinya dapat menghasilkan produk bermutu dengan proses produksi yang efektif dan efisien agar terus dapat memuaskan konsumennya dan tetap terus bersaing, serta memenangkan kompetisi di dunia industri sehingga bisa menjadi sebuah perusahaan berkelas dunia world class manufacturing yang mampu bersaing dengan perusahaan dari negaranegara lain.

Untuk mendukung kegiatan tersebut, bagian produksi dituntut untuk dapat meningkatkan efisiensi dan mutu produk, agar diperoleh produk yang diinginkan dengan biaya serendah mungkin adalah dengan menghilangkan pemborosan.

Setiap perusahaan tentu ingin mendapatkan hasil yang maksimal dalam pencapaian mutu maupun jumlah produksi yang dihasilkan. Hal ini mungkin dapat tercapai apabila tidak ada permasalahan pada mesin maupun peralatannya, akan tetapi pada kenyatannya masih banyak ditemukan hambatan-hambatan ataupun kerusakan yang menyebabkan produk menjadi cacat bahkan produksi berhenti untuk sementara waktu dan bahkan terjadi breakdown.

Terdapat banyak faktor-faktor yang mendukung untuk tercapainya efektivitas perawatan. Dalam hal ini, pengukuran tentu yang sesuai dengan semua kondisi dan faktor yang kompleks diatas. Untuk menghitung dan meningkatkan level efektivitas pada akhirnya, maka perlu dilakukan pendekatan. Salah satu pendekatan yang digunakan adalah pengukuran Overall Equipment Effectiveness (OEE) sebagai produk dari Total Productive Maintenance (TPM) yang konsepnya diperkenalkan oleh Seiichi Nakajima pada tahun 1971.

PT XYZ merupakan perusahaan yang bergerak di bidang industri kosmetik yang memproduksi produk skincare, pancake, eye shadow, lipstik. Dan memproduksi dengan menerima pesanan dari perusahaan rekanan melalui kerjasama makloon. Agar perusahaan selalu dapat menjaga mutunya, perusahaan wajib melakukan pengontrolan secara kontinu untuk semua tahapan proses yang ada. Keterkaitan antar departemen Production Planning and Inventory (PPIC), Produksi, Teknik dan
Quality Control $(Q C)$ merupakan keharusan, agar dihasilkan produk secara optimal dengan mutu sesuai standar.

PT XYZ selama ini belum pernah mengukur nilai efektivitas peralatan atau mesin pada lini proses produksinya, sehingga dapat mengakibatkan kerugian bagi PT XYZ. Perusahaan ini sangat bergantung pada proses produksi skincare. Karena banyaknya produk makloon yang bisa menambah keuntungan perusahaan.

\section{STUDI LITERATUR}

\section{Six Big Losses (Enam Kerugian Besar)}

Kegiatan dan tindakan-tindakan yang dilakukan dalam TPM tidak hanya berfokus pada pencegahan terjadinya kerusakan pada mesin/peralatan dan meminimalkan downtime mesin/peralatan. Akan tetapi banyak faktor yang dapat menyebabkan kerugian akibat rendahnya efisien mesin/peralatan. Rendahnya produktivitas mesin/peralatan yang menimbukan kerugian bagi perusahaan sering diakibatkan oleh pengguanaan mesin/peralatan yang tidak efektif dan efisien yang mengakibatkan enam faktor kerugian (six big losses). Efisiensi adalah ukuran yang menunjukan bagaimana sebaiknya sumber-sumber daya digunakan dalam proses produksi untuk menghasiljan output. (Nakajima, 1988).

1) Downtime (Penurunan Waktu)

a. Equipment failur/breakdown (Kerugian karena kerusakan pada mesin/peralatan )

b. Set up and adjustment (Kerugian karena pemasangan dan penyetelan)

2) Speed Losses ( Penurunan Kecapatan)

a. Idling and minor stoppages (kerugian karena beroperasi tanpa beban maupun berhenti sesaat).

b. Reduced speed (kerugian karena mesin tidak bekerja optimal (penurunan kecepatan operasi)

3) Defect (Cacat)

a. Process Defect (Kerugian karena produk cacat maupun karena kerja produk di proses ulang)

b. Reduced Yield Losses ( Kerugian material yang tidak dipakai atau sampah bahan baku)

Berikut ini merupakan penjelasan dari 6 faktor six big losses, antara lain: 
1) Equipment failur/breakdown (Kerugian karena kerusakan mesin)

Kerusakan mesin/peralatan akan mengakibatkan waktu yang terbuang sia-sia yang mengakibatkan kerugian bagi perusahaan akibat berkurangnya volume produksi atau kerugian material akibat produksi yang cacat. (S.Nakajima,1988).

\section{2) Set up and Adjustment Losses (Kerugian} karena pemasangan dan penyetelan)

Kerugian karena set up and adjusment losses adalah semua waktu set up termasuk waktu penyesuaian (adjusment) dan juga waktu yang dibutuhkan untuk kegiatankegiatan mengganti suatu jenis produk ke jenis produk berikutnya untuk produksi selanjutnya. Dengan kata lain total yang dibutuhkan mesin tidak berproduksi selanjutnya. Dengan kata lain total yang dibutuhkan mesin tidak berproduksi guna mengganti peralatan bagi jenis produk berikutnya sampai dihasilkan produk selanjutnya.(Nakajima, 1988).

3) Idling and minor stoppages (Kerugian karena beroperasi tanpa beban maupun karena berhenti sesaat)

Kerugian karena beroperasi tanpa beban maupun berhenti sesaat muncul jika faktor eksternal mengakibatkan mesin/peralatan berhenti berulang-ulang atau mesin/peralatan beroperasi tanpa menghasilkan produk. (Nakajima, 1988).

\section{4) Reduced Speed Losses ( Kerugian} karena beroperasi tanpa beban maupun karena berhenti sesaat)

Menurunnya kecepatan produksi timbul jika kecepatan operasi aktual lebih kecil dari kecepatan mesin yang telah dirancang beroperasi dalam kecepatan normal. Menurunnya kecepatan mesin dapat diakibatkan oleh (Nakajima, 1988):

a. Kecepatan mesin yang dirancang tidak dapat dicapai karrena berubahnya jenis produk atau material yang tidak sesuai dengan mesin/peralatan yang digunakan.

b. Kecepatan produksi mesin menurun akibat operator tidak mengetahui berapa kecepatan normal mesin/peralatan sesungguhnya.

c. Kecepatan produksi sengaja dikurangi untuk mencegah timbulnya masalah pada mesin/peralatan dan kualitas produk yang dihasilkan jika produksi pada kecepatan produksi yang lebih tinggi.

5) Process Defect Losses (Kerugian karena produk cacat maupun karena kerja produk di proses ulang)

Produk cacat yang dihasilkan akan mengakibatkan kerugian material, mengurangi jumlah produksi, limbah produksi meningkat dan biaya untuk pengerjaan ulang. Kerugian akibat pengerjaan ulang termasuk biaya tenaga kerja dan waktu yang dibutuhkan untuk mengelola dan mengerjakan kembali ataupun memperbaiki produk yang cacat hal ini akan menjadi masalah besar. (Nakajima, 1988).

6) Reduced Yield Losses (Kerugian akibat pada awal waktu produksi hingga mencapai kondisi produksi yang stabil)

Reduced Yield Losses adalah kerugian waktu dan meteril yang timbul selama waktu yang dibutuhkan oleh mesin/peralatan untuk menghasilkan produk baru dengan kualitas produk yang telah diharapkan. Kerugian yang timbul tergantung pada faktor-faktor seperti keadaan operasi yang tidak stabil, tidak tepat penanganan dan pemasangan mesin/peralatan ataupun operator tidak mengerti dengan kegiatan proses produksi yang dilakukan. (Nakajima, 1988).

\section{Overall Equipment Efectiviness (OEE)}

OEE merupakan ukuran menyeluruh yang didefinisikan tingkat produktivitas mesin/peralatan dan kinerja secara teori. Pengukuran ini sangat penting untuk mengetahui area aman yang perlu ditingkatkan produktivitasnya

Formula matematis dari Overall Equipment Efectiviness (OEE) di rumuskan sebagai berikut:

OEE $=$ Availability $\times$ Performence Eficiency

$x$ Rate of Quality Product x $100 \%$

1) Availability

Perhitungan Net Operating time membutuhkan nilai dari:

a. Planned downtime;

b. Clean machine;

c. Change over;

d. Machine break; dan

e. External Couses.

Waktu yang tersedia (availability) per hari atau perbulan dengan waktu downtime 
mesin direncanakan (planed donwtime).

\section{Loading time $=$ Total availability - Planned downtime)

Planned downtime adalah jumlah waktu downtime mesin untuk pemeliharaan (scheduled maintenance) atau kegiatan manajemen lainya.

Nilai Operating Time dengan rumus sebagai berikut:

Operating Time = Loading time Downtime

Nilai \% Availability dihitung dengan rumus sebagai berikut:

$$
\text { Avaialbility }=\frac{\text { operating time }}{\text { Loading time }} \times 100 \% \text {...... }
$$

2) Peformance Efficiency

Rasio kualitas produk dihasilkan dikalikan dengan waktu siklus idealnya terhadap waktu yang tersedia yang melakukan proses produksi (operation time).

Performance efficiency $=$ (process a mount $x$ ideal cycletime) operationtime

\section{3) Rate of Quality Product}

Adalah rasio jumlah produk yang lebih baik terhadap jumlah total produk yang di proses. Jadi rate of quality product adalah hasil perhitungan dengan menggunakan dua faktor berikut:

Rate of quality product $=$ (processed amount-defect amount) $X 100 \%$ processed amount

\section{Definisi Seven Tools (Tujuh Alat Bantu)}

Berikut ini seven tools (tujuh alat bantu) yang digunakan menganalisa data-data yang telah diolah pada penelitian ini, yaitu diagram sebab akibat (fish bone), peta kendali p, dan diagram pareto.

\section{1) Peta Kendali $p$}

Peta kendali $\mathrm{p}$ adalah suatu peta yang menunjukan cacat pecahan (p) dimana sub ukuran tidak konstan.

$$
\begin{aligned}
& p=\frac{\text { (total produk cacat) }}{\text { total produk diinspeksi }} \\
& \mathrm{CL}=\mathrm{p} \\
& U C L=p+3 \sqrt{\frac{p(1-p)}{n}} \\
& L C L=p-3 \sqrt{\frac{p(1-p)}{n}}
\end{aligned}
$$

2) Nilai Cp dan $c p k$

a. Capability Process Index (Cp)

Indek kapabilitas proses atau disebut Capability Process Index ( $C p$ ) adalah indeks yang menunjukan kemampuan proses dalam menghasilkan produk/output yang sesuai dengan spesifikasi.

$\mathrm{Cp}=\frac{\text { Batas USL }- \text { Batas } L S L}{6 \sigma}$

USL = Upper Spacification Limit

LSL $=$ Lower Specification Limit

$\sigma \quad=$ Standar deviasi

Kriteria penilaian $\mathrm{Cp}$ :

a) Jika $\mathrm{Cp}>1,33$, maka kapabilitas proses sangat baik

b) Jika $1,00 \leq \mathrm{Cp} \leq 1,33$, maka kapabilitas proses baik

c) Jika $\mathrm{Cp}<1,00$, maka kapabilitas proses rendah

b. Indeks Cpk:

Rumus matematik untuk menghitung indeks Cpk sebagai berikut:

$\mathrm{Cpk}=\min \left[\frac{\text { batas USL-p }}{3 \sigma}, \frac{p-\text { batas LSL }}{3 \sigma}\right]$

$\mathrm{USL}=$ Upper Spacification Limit

$\mathrm{LSL}=$ Lower Specification Limit

$\sigma \quad=$ standar deviasi

Kriteria penilaian Cpk:

a) Jika $\mathrm{Cpk}=\mathrm{Cp}$, maka proses terjadi ditengah

b) Jika Cpk = 1 maka proses menghasilkan produk yang sesuai dengan spesifikasi

c) Jika Cpk < 1 maka proses menghasilkan produk yang tidak sesuai dengan spesifikasi

d) Kondisi ideal ; $\mathrm{Cp}>1,33$ dan $\mathrm{Cp}=\mathrm{Cpk}$

\section{METODOLOGI PENELITIAN}

Metode penelitian yang digunakan dalam penelitian ini adalah mulai dari pengamatan di produksi sampai perhitungan OEE hingga memberikan usulan perbaikan untuk meningkatkan nilai OEE dan membuat prosedur perhitungan OEE. Pengamatan yang dilakukan adalah mengetahui kondisi produksi, alur proses produksi, jenis kecacatan produksi, jenis dwontime, dan sistem pendataan laporan produksi. Studi literatur kemudian dilakukan untuk memperoleh sumber informasi yang berkaitan dengan pengukuran performa 
produksi menggunakan OEE dan teori-teori penunjang penelitian. Langkah selanjutnya adalah mengumpulkan data yang dibutuhkan berdasarkan studi literatur yang telah dilakukan. Data-data yang telah dikumpulkan melalui arsip perusahaan, pengamatan dan wawancara kemudian diolah untuk memperoleh nilai dari ketiga faktor OEE yaitu availability, performance rate, quality rate. Analisa hasil perhitungan OEE dilakukan untuk menganalisa produktivitas proses produksi di perusahaan.

Pada tahap ini data dikumpulkan berdasarkan data hasil dari Departemen produksi bagian produksi skincare di PT XYZ pada bulan Maret 2017- November 2017.

Tabel 1 Data produksi skincare Bulan Maret- November 2017

\begin{tabular}{lc}
\hline Bulan & $\begin{array}{c}\text { Processed } \\
\text { Amount }(\mathrm{pcs})\end{array}$ \\
\hline Maret & 29.663 \\
April & 27.838 \\
Mei & 40.202 \\
Juni & 54.484 \\
Juli & 45.058 \\
Agustus & 38.563 \\
September & 34.578 \\
Oktober & 37.449 \\
November & 42.924 \\
\hline
\end{tabular}

\section{Menghitung Overall Equipment Effec- tiviness (OEE)}

Dari hasil pengamatan pada mesin ultrasonic rotary dan alpha pack di stasiun pengisian, faktor-faktor yang menyebabkan delay pada mesin tersebut adalah:

a. Change over yaitu waktu pergantian produk,setting mesin.

b. Clean machine yaitu pembersihan mesin ketika pergantian produk

c. External yaitu berhentinya operasi mesin diakibatkan gangguan listrik dari PLN.

d. Machine Break yaitu kerusakan terhadap mesin yang menyebabkan mesin berhenti beroperasi untuk sementara waktu.

e. Planned downtime yaitu waktu downtime yang telah dijadwalkan dalam rencana produksi.

f. Warm up time yaitu waktu persiapan mesin sebelum beroperasi.

\section{1) Perhitungan Availability ratio}

Merupakan suatu rasio yang menggambarkan pemanfaatan waktu yang tersedia untuk kegiatan operasi mesin.

Loading time $=3840-400=3440$ menit

Nilai Operating Time dihitung menggunakan rumus (2.3).

Operating time $=3440-816=2624$ menit

Tabel 2 Perhitungan downtime

\begin{tabular}{lcccccc}
\hline Bulan & $\begin{array}{c}\text { Change } \\
\text { Over } \\
\text { (menit) }\end{array}$ & $\begin{array}{c}\text { Clean } \\
\text { Machine } \\
\text { (menit) }\end{array}$ & $\begin{array}{c}\text { External } \\
\text { Causes } \\
\text { (menit) }\end{array}$ & $\begin{array}{c}\text { Machine } \\
\text { Break } \\
\text { (menit) }\end{array}$ & $\begin{array}{c}\text { Warm up } \\
\text { Time } \\
\text { (menit) }\end{array}$ & $\begin{array}{c}\text { Downtime } \\
\text { (menit) }\end{array}$ \\
\hline Maret & 60 & 120 & 216 & 300 & 120 & 816 \\
April & 144 & 180 & 80 & 160 & 100 & 664 \\
Mei & 150 & 156 & 150 & 210 & 175 & 841 \\
Juni & 132 & 156 & 180 & 420 & 145 & 1033 \\
Juli & 300 & 150 & 210 & 324 & 100 & 1084 \\
Ags & 144 & 135 & 72 & 144 & 120 & 615 \\
Sept & 144 & 126 & 75 & 60 & 120 & 525 \\
Okt & 72 & 162 & 210 & 126 & 120 & 690 \\
Nov & 132 & 132 & 270 & 276 & 100 & 910 \\
\hline
\end{tabular}

Tabel 3 Availability pada proses produksi skincare

\begin{tabular}{lcccc}
\hline Bulan & $\begin{array}{c}\text { Loading } \\
\text { time } \\
\text { (menit) }\end{array}$ & $\begin{array}{c}\text { Down } \\
\text { Time } \\
\text { (menit) }\end{array}$ & $\begin{array}{c}\text { Operating } \\
\text { Time } \\
\text { (menit) }\end{array}$ & $\begin{array}{c}\text { Availability } \\
\text { (\%) }\end{array}$ \\
\hline Maret & 3440 & 816 & 2624 & 76,28 \\
April & 3440 & 664 & 2776 & 80,70 \\
Mei & 4730 & 841 & 3889 & 82,22 \\
Juni & 5590 & 1033 & 4557 & 81,52 \\
Juli & 5160 & 1084 & 4076 & 78,99 \\
Ags & 4300 & 615 & 3685 & 85,70 \\
Sep & 3440 & 525 & 2915 & 84,74 \\
Okt & 3870 & 690 & 3180 & 82,17 \\
Nov & 4730 & 910 & 3820 & 80,76 \\
\hline
\end{tabular}

Tabel 4 Perhitungan Loading Time

\begin{tabular}{lccc} 
Bulan & $\begin{array}{c}\text { Availablity } \\
\text { time } \\
\text { (menit) }\end{array}$ & $\begin{array}{c}\text { Planned } \\
\text { downtime } \\
\text { (menit) }\end{array}$ & $\begin{array}{c}\text { Loading } \\
\text { Time } \\
\text { (menit) }\end{array}$ \\
\hline Maret & 3840 & 400 & 3440 \\
April & 3840 & 400 & 3440 \\
Mei & 5280 & 550 & 4730 \\
Juni & 6240 & 650 & 5590 \\
Juli & 5760 & 600 & 5160 \\
Ags & 4800 & 500 & 4300 \\
Sep & 3840 & 400 & 3440 \\
Okt & 4320 & 450 & 3870 \\
Nov & 5280 & 550 & 4730 \\
\hline
\end{tabular}

2) Perhitungan Performance

Perhitungan Performance eficiency dimulai dengan perhitungan ideal cycle time. 
Ideal cycle time merupakan waktu siklus ideal mesin. Kapasitas mesin 1 menit bisa memproduksi 12 pcs .

Ideal cycle time $=\frac{1 \text { menit }}{12 \text { pes }}=0,083$ menit $/ \mathrm{pcs}$

Perhitungan performance efficiency menggunakan rumus (2.7).

Performance efficiency

\section{$=\frac{29663 x 0,083}{2624} \times 100 \%=93,82 \%$}

Tabel 5 Perhitungan Performance

\begin{tabular}{lcccc}
\hline Bulan & $\begin{array}{c}\text { Proses } \\
\text { Amount } \\
\text { (pcs) }\end{array}$ & $\begin{array}{c}\text { Operating } \\
\text { Time } \\
\text { (menit) }\end{array}$ & $\begin{array}{c}\text { Ideal Cycle } \\
\text { Time (menit/ } \\
\text { pcs) }\end{array}$ & $\begin{array}{c}\text { Performance } \\
\text { (\%) }\end{array}$ \\
\hline Maret & 29.663 & 2624 & 0.083 & 93,83 \\
April & 27.838 & 2776 & 0.083 & 83,23 \\
Mei & 40.202 & 3889 & 0.083 & 85,80 \\
Juni & 54.484 & 4557 & 0.083 & 99,24 \\
Juli & 45.058 & 4076 & 0.083 & 91,75 \\
Ags & 38.563 & 3685 & 0.083 & 86,86 \\
Sept & 34.578 & 2915 & 0.083 & 98,46 \\
Okt & 37.449 & 3180 & 0.083 & 97,74 \\
Nov & 42.924 & 3820 & 0.083 & 93,26 \\
\hline
\end{tabular}

3) Perhitungan Rate of Quality product

Rate of Quality Product merupakan rasio yang menggambarkan kemampuan peralatan dalam menghasilkan produk dengan sesuai standar. Menghitung Rate of Quality Product menggunakan rumus (2.8)

Perhi-tungan Rate of Quality Product $=$ $\frac{29663-1439}{29663} \times 100 \%=95,15 \%$

Yang termasuk reject adalah produk cacat, yang mana kualifikasi produk cacat terbagi menjadi 3 yaitu: reject $\mathrm{QC}$, reject isi, dan reject kosong.

\begin{tabular}{lccc}
\multicolumn{4}{c}{ Tabel 6 Perhitungan ROQ } \\
\hline Bulan & $\begin{array}{c}\text { Processed } \\
\text { Amount } \\
\text { (Unit) }\end{array}$ & $\begin{array}{c}\text { Reject } \\
\text { (Unit) }\end{array}$ & $\begin{array}{c}\text { Quality } \\
\text { (\%) }\end{array}$ \\
\hline Maret & 29.663 & 1.439 & 95,15 \\
April & 27.838 & 1.918 & 93,11 \\
Mei & 40.202 & 1.322 & 96,71 \\
Juni & 54.484 & 2.644 & 95,15 \\
Juli & 45.058 & 1.858 & 95,88 \\
Ags & 38.563 & 1.123 & 97,09 \\
Sept & 34.578 & 2.322 & 93,28 \\
Okt & 37.449 & 1.161 & 96,90 \\
Nov & 42.924 & 1.452 & 96,62 \\
\hline
\end{tabular}

4) Perhitungan OEE

$\mathrm{OEE}=76,28 \%+93,83 \%+95,15 \%=$ $68,10 \%$.
Tabel 7 Perhitungan OEE bulan Maret - November 2017

\begin{tabular}{lcccc}
\hline Bulan & $\begin{array}{c}\text { Availability } \\
\text { (\%) }\end{array}$ & $\begin{array}{c}\text { Performance } \\
\text { (\%) }\end{array}$ & $\begin{array}{c}\text { Quality } \\
\text { (\%) }\end{array}$ & $\begin{array}{c}\text { OEE } \\
\text { (\%) }\end{array}$ \\
\hline Maret & 76,28 & 93,83 & 95,15 & 68,10 \\
April & 80,70 & 83,23 & 93,11 & 62,54 \\
Mei & 82,22 & 85,80 & 96,71 & 68,22 \\
Juni & 81,52 & 99,24 & 95,15 & 76,97 \\
Juli & 78,99 & 91,75 & 95,88 & 69,49 \\
Ags & 85,70 & 86,86 & 97,09 & 72,27 \\
Sep & 84,74 & 98,46 & 93,28 & 77,83 \\
Okt & 82,17 & 97,74 & 96,90 & 77,82 \\
Nov & 80,76 & 93,26 & 96,62 & 72,77 \\
\hline
\end{tabular}

\section{Perhitungan Six Big Losses}

1) Downtime Losses

Didalam perhitungan Six Big Losses, yang termasuk dalam downtime losses adalah equipment failure dan set up and adjusment.

Equipment failure los $=\frac{\text { total breakkdown time }}{\text { loading time }} \times 100 \%$

Tabel 8 Perhitungan Total Breakdown Time

\begin{tabular}{lccc}
\hline Bulan & $\begin{array}{c}\text { External } \\
\text { Cause } \\
\text { (menit) }\end{array}$ & $\begin{array}{c}\text { Machine } \\
\text { Break } \\
\text { (Menit) }\end{array}$ & $\begin{array}{c}\text { Total } \\
\text { Breakdown } \\
\text { (menit) }\end{array}$ \\
\hline Maret & 216 & 300 & 516 \\
April & 80 & 160 & 240 \\
Mei & 150 & 210 & 360 \\
Juni & 180 & 420 & 600 \\
Juli & 210 & 324 & 534 \\
Agustus & 72 & 144 & 216 \\
September & 75 & 60 & 135 \\
Oktober & 210 & 126 & 336 \\
November & 270 & 276 & 546 \\
\hline
\end{tabular}

Set up and adjusment loss $=\frac{\text { waktu setting }}{\text { loadingtime }} \times 100 \%$

180

$\frac{180}{3440} \times 100 \%=5,23 \%$

Tabel 9 Perhitungan Set up and Adjusment

\begin{tabular}{lccc}
\hline Bulan & $\begin{array}{c}\text { Set up and } \\
\text { Adjusment } \\
\text { (menit) }\end{array}$ & $\begin{array}{c}\text { Loading } \\
\text { Time } \\
\text { (menit) }\end{array}$ & $\begin{array}{c}\text { Set up } \\
\text { Losses } \\
\text { (\%) }\end{array}$ \\
\hline Maret & 180 & 3440 & 5,23 \\
April & 244 & 3440 & 7,09 \\
Mei & 325 & 4730 & 6,87 \\
Juni & 277 & 5590 & 4,96 \\
Juli & 400 & 5160 & 7,75 \\
Ags & 264 & 4300 & 6,14 \\
Sep & 264 & 3440 & 7,67 \\
Okt & 192 & 3870 & 4,96 \\
November & 232 & 4730 & 4,90 \\
& 2378 & & \\
\hline
\end{tabular}

Equipment failure loss $=\frac{516}{3440} x 100 \%=15,00 \%$ 
Tabel 10 Perhitungan Equipment Failure Loss

\begin{tabular}{lccc}
\hline Bulan & $\begin{array}{c}\text { Total } \\
\text { Breakdown } \\
\text { (menit) }\end{array}$ & $\begin{array}{c}\text { Loading } \\
\text { Time(menit) }\end{array}$ & $\begin{array}{c}\text { Breakdown } \\
\text { Loss (\%) }\end{array}$ \\
\hline Maret & 516 & 3440 & 15,00 \\
April & 240 & 3440 & 6,98 \\
Mei & 360 & 4730 & 7,61 \\
Juni & 600 & 5590 & 10,73 \\
Juli & 534 & 5160 & 10,35 \\
Agustus & 216 & 4300 & 5,02 \\
September & 135 & 3440 & 3,92 \\
Oktober & 336 & 3870 & 8,68 \\
November & 546 & 4730 & 11,54 \\
& 3483 & & \\
\hline
\end{tabular}

2) Speed Losses

Faktor- faktor yang dikatagorikan dalam speed losses adalah idling and minor stoppage (clean machine/sanitasi mesin) dan reduced speed losses.

a. Idling and Minor Stoppage Loss

$$
\begin{aligned}
& =\frac{\text { Non productive Tims }}{\text { Lauding Tims }} \times 100 \% \\
& \frac{120}{3440} \times 100 \%=3,49 \%
\end{aligned}
$$

Tabel 11 Persentase Idling and Minor Stoppage

\begin{tabular}{cccc}
\hline Bulan & $\begin{array}{c}\text { Clean } \\
\text { Machine } \\
\text { (menit) }\end{array}$ & $\begin{array}{c}\text { Loading } \\
\text { Time } \\
\text { (menit) }\end{array}$ & $\begin{array}{c}\text { Minor } \\
\text { Stoppage } \\
\text { Losses } \\
\text { (\%) }\end{array}$ \\
\hline Maret & 120 & 3440 & 3,49 \\
April & 180 & 3440 & 5,23 \\
Mei & 156 & 4730 & 3,30 \\
Juni & 156 & 5590 & 2,79 \\
Juli & 150 & 5160 & 2,91 \\
Ags & 135 & 4300 & 3,14 \\
Sep & 13 & 3440 & 0,37 \\
Okt & 162 & 3870 & 4,19 \\
Nov & 132 & 4730 & 2,79 \\
Jumlah & 1204 & & \\
\hline
\end{tabular}

b. Reduced Speed Losses

Reduced Speed Losses dihitung dengan rumus Reduced Speed Losses $=$

operation Time-(Ideal CyeleTime $x$ Finish Goad) Laading Time $x 100 \%$

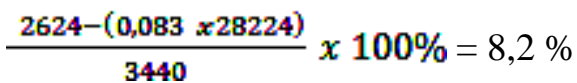

Tabel 12 Perhitungan Persentase Reduced Speed Losses

\begin{tabular}{lcccccc}
\hline Bulan & $\begin{array}{c}\text { Operation } \\
\text { Time } \\
\text { (Menit) }\end{array}$ & $\begin{array}{c}\text { Waktu } \\
\text { Siklus } \\
\text { Ideal } \\
\text { (Menit) }\end{array}$ & $\begin{array}{c}\text { Finnish } \\
\text { Good } \\
\text { (pcs) }\end{array}$ & $\begin{array}{c}\text { Loading } \\
\text { Time } \\
\text { (menit) }\end{array}$ & $\begin{array}{c}\text { Reduced } \\
\text { Speed } \\
\text { Losses } \\
\text { (menit) }\end{array}$ & $\begin{array}{c}\text { Reduced } \\
\text { Speed } \\
\text { Losses } \\
\text { (\%) }\end{array}$ \\
\hline Maret & $\mathbf{2 6 2 4}$ & 0,083 & 28.224 & 3440 & 281 & 8,2 \\
April & 2776 & 0,083 & 25.920 & 3440 & 625 & 18,2 \\
Mei & 3889 & 0,083 & 38.880 & 4730 & 662 & 14,0 \\
Juni & 4557 & 0,083 & 51.840 & 5590 & 255 & 4,6 \\
Juli & 4076 & 0,083 & 43.200 & 5160 & 491 & 9,5 \\
Ags & 3685 & 0,083 & 37.440 & 4300 & 578 & 13,4 \\
Sep & 3028 & 0,083 & 32.256 & 3440 & 351 & 10,2 \\
Okt & 3180 & 0,083 & 36.288 & 3870 & 169 & 4,4 \\
Nov & 3820 & 0,083 & 41.472 & 4730 & 378 & 8,0 \\
Jumlah & & & & & 3791 & \\
\hline
\end{tabular}

3) Defect losses

a. Process Defect atau Rework loss

Process defect $=$

Ideal cycle time-Process defect Loading Time $x 100 \%$

Tabel 13 Perhitungan Persentase Process Defect atau rework loss

\begin{tabular}{lccc}
\hline Bulan & $\begin{array}{c}\text { Loading } \\
\text { Time } \\
\text { (menit) }\end{array}$ & $\begin{array}{c}\text { Waktu } \\
\text { Siklus } \\
\text { Ideal } \\
\text { (Menit) }\end{array}$ & $\begin{array}{c}\text { Process } \\
\text { Defect } \\
\text { /Rework } \\
\text { (pcs) }\end{array}$ \\
\hline Maret & 3440 & 0,083 & 0 \\
April & 3440 & 0,083 & 0 \\
Mei & 4730 & 0,083 & 0 \\
Juni & 5590 & 0,083 & 0 \\
Juli & 5160 & 0,083 & 0 \\
Ags & 4300 & 0,083 & 0 \\
Sep & 3440 & 0,083 & 0 \\
Okt & 3870 & 0,083 & 0 \\
Nov & 4730 & 0,083 & 0 \\
\hline
\end{tabular}

b. Yield atau Scrap Loss

Untuk mengetahui persentase faktor yield atau scrap losses yang mempengaruhi efektivitas mesin, maka digunakan rumus:

$$
\begin{aligned}
\text { Yield } & =\frac{\text { Ideal Gycle Time } x \text { Yield/Scrap) }}{\text { Laading Time }} \times 100 \% \\
& =\frac{0,083 \times 1,4}{2440} \times 100 \%=0.003 \%
\end{aligned}
$$

Tabel 14 Perhitungan Persentase Yield atau scrap Losses

\begin{tabular}{lcccc}
\hline Bulan & $\begin{array}{c}\text { Loading time } \\
\text { (menit) }\end{array}$ & $\begin{array}{c}\text { Waktu Siklus } \\
\text { Ideal } \\
\text { (Menit/pcs) }\end{array}$ & $\begin{array}{c}\text { Yield/Scrap } \\
\text { (kg) }\end{array}$ & $\begin{array}{c}\text { Scrap } \\
\text { Loss } \\
\text { (\%) }\end{array}$ \\
\hline Maret & 3440 & 0,083 & 1,40 & 0,003 \\
April & 3440 & 0,083 & 1,92 & 0,005 \\
Mei & 4730 & 0,083 & 1,32 & 0,002 \\
Juni & 5590 & 0,083 & 2,64 & 0,004 \\
Juli & 5160 & 0,083 & 1,86 & 0,003 \\
Ags & 4300 & 0,083 & 1,12 & 0,002 \\
Sep & 3440 & 0,083 & 2,32 & 0,006 \\
Okt & 3870 & 0,083 & 1,16 & 0,003 \\
Nov & 4730 & 0,083 & 1,45 & 0,003 \\
& & Jumlah & & \\
\hline
\end{tabular}




\section{Pengaruh Six Big Losses}

Untuk lebih jelas six big losses yang mempengaruhi efektifitas mesin, maka akan dilakukan perhitungan time loss untuk masing-masing faktor dalam six big losses tersebut seperti yang dilihat pada hasil di tabel 15.

Tabel 15. Persentase Faktor Six Big losses Mesin Filling skincare

\begin{tabular}{lccc}
\hline \multicolumn{1}{c}{ Six Big Losses } & $\begin{array}{c}\text { Total time } \\
\text { losses (menit) }\end{array}$ & $\begin{array}{c}\text { Persentase } \\
(\%)\end{array}$ & $\begin{array}{c}\% \\
\text { Komulatif }\end{array}$ \\
\hline Reduced speed losses & 3791 & 34,92 & 34,92 \\
Equipment failur & 3483 & 32,08 & 67,00 \\
Set up and adjusment & 2378 & 21,90 & 88,90 \\
Idling and Minor Stoppages & 1204 & 11,09 & 99,99 \\
Reduced yield losses & 1,267 & 0,01 & 100,00 \\
Proses defect losses & 0 & 0,00 & 100,00 \\
\hline
\end{tabular}

Persantase time loss dari keenam faktor tersebut diperlihatkan dalam bentuk diagram pareto.

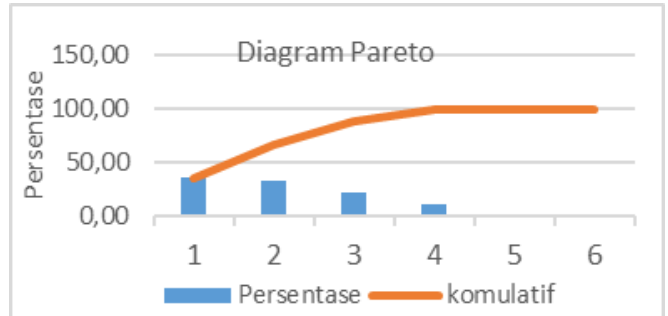

Gambar 1 Diagram pareto Six Big Losses Mesin filling Skincare

Dari pengurutan diatas bahwa faktor yang memiliki persentase terbesar dari ke enam faktor tersebut adalah reduced, breakdown, set up and adjusment, dan idling and Minor Stoppage.

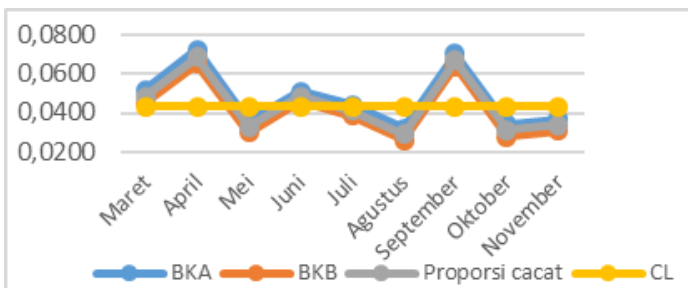

Gambar 2 Grafik Peta kendali p data cacat mesin filling Skincare

\section{4) Peta Kendali $p$}

Peta kendali yang digunakan adalah peta kendali $p$ karena data cacat yang digunakan berupa data variabel.

$\dot{\boldsymbol{p}}=\frac{\text { totaljumlahyangditolak }}{\text { total jumlahyangdiperiksa }}=\frac{152 \mathrm{ag}}{\mathbf{3 5 0 7 5 9}}=0,04344$.

$\mathrm{BKA}=\mathrm{p}+3 \sigma=0,0485+0,0035=0,0521$

$\mathrm{BKB}=\mathrm{p}-3 \sigma=0,0485-0,0035=0,0450$

Tabel 16. Perhitungan dengan Peta kendali $\mathrm{p}$

\begin{tabular}{lccccccc}
\hline Bulan & $\begin{array}{c}\text { Tube yg } \\
\text { diperiksa (n) }\end{array}$ & Reject & $\mathbf{p}$ & $\mathbf{3} \sigma=3 \sqrt{\frac{(1+p)}{n}}$ & CL & BKA & BKB \\
\hline Maret & 29.663 & 1.439 & 0,0485 & 0,0035 & 0,0434 & 0,0521 & 0,0450 \\
April & 27.838 & 1.918 & 0,0689 & 0,0036 & 0,0434 & 0,0725 & 0,0653 \\
Mei & 40.202 & 1.322 & 0,0329 & 0,0031 & 0,0434 & 0,0359 & 0,0298 \\
Juni & 54.484 & 2.644 & 0,0485 & 0,0026 & 0,0434 & 0,0511 & 0,0459 \\
Juli & 45.058 & 1.858 & 0,0412 & 0,0029 & 0,0434 & 0,0441 & 0,0383 \\
Agts & 38.563 & 1.123 & 0,0291 & 0,0031 & 0,0434 & 0,0323 & 0,0260 \\
Sep & 34.578 & 2.322 & 0,0672 & 0,0032 & 0,0434 & 0,0704 & 0,0639 \\
Okt & 37.449 & 1.161 & 0,0310 & 0,0032 & 0,0434 & 0,0342 & 0,0278 \\
Nov & 42.924 & 1.452 & 0,0338 & 0,0030 & 0,0434 & 0,0368 & 0,0308 \\
& & & & & & &
\end{tabular}

Tahap selanjutnya adalah perhitungan kapabilitas proses data didapat dari berat per tube yang di timbang 10 pcs perbulan untuk mengetahui stabil atau tidaknya berat per tube.

Perhitungan kapabilitas proses dengan mencari rata-rata dari sampel yang telah diambil. Jumlah total dari sampel $\sum \mathrm{Xi}$ $=8645,4$. Kemudian rata-ratanya dapat dicari dengan formula $=8645,4 / 9=96$.

Tabel 17. Tabel Data hasil Observasi berat per tube (gram)

\begin{tabular}{lcccccccccc}
\hline \multirow{2}{*}{ Bulan } & \multicolumn{10}{c}{ Berat per tube (gram) } \\
\cline { 2 - 10 } Maret & 1 & 2 & 3 & 4 & 5 & 6 & 7 & 8 & 9 & 10 \\
April & 95,5 & 96,8 & 95,1 & 95,8 & 95,7 & 96,2 & 95,7 & 95,7 & 96,1 & 96,0 \\
Mei & 95,0 & 96,9 & 96,9 & 95,0 & 96,8 & 96,2 & 95,2 & 95,6 & 95,8 & 95,8 \\
Juni & 95,7 & 95,8 & 95,9 & 96,7 & 95,7 & 96,8 & 95,7 & 95,0 & 95,8 & 97,0 \\
Juli & 96,7 & 96,8 & 96,2 & 95,6 & 97,0 & 96,7 & 96,8 & 96,0 & 95,4 & 95,7 \\
Agustus & 97,0 & 95,9 & 95,7 & 96,3 & 96,8 & 97,0 & 95,0 & 95,6 & 95,0 & 96,0 \\
September & 96,0, & 97,0 & 95,4 & 96,7 & 95,3 & 95,6 & 96,0 & 97,3 & 95,6 & 97,0 \\
Oktober & 97,0 & 95,0 & 95,8 & 95,6 & 95,0 & 96,7 & 97,5 & 95,7 & 95,6 \\
November & 97,5 & 96,5 & 95,7 & 95,7 & 96,7 & 95,4 & 96,7 & 95,0 & 95,4 & 97,5 \\
\hline
\end{tabular}

Kemudian mencari standar deviasi dari semua sample dengan formula sebagai berikut:

$\mathrm{S}$

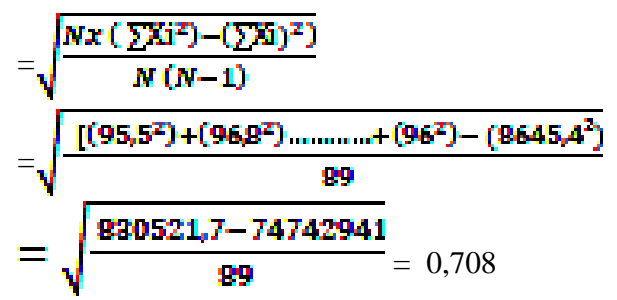

Batas-batas USL dan LSL sudah ditetapkan perusahaan sebesar 95 gram - 97,5 gram.

$$
\begin{aligned}
\mathrm{Cp}= & \frac{\text { Batas USL-Batas } L S L}{6 \sigma}=\frac{97,5-95}{6 x 0,708}=0,588 \\
\mathrm{Cpk} & =\min \left[\frac{\text { batas USL }-p}{3 \sigma}, \frac{p-\text { batas LSL }}{3 \sigma}\right] \\
& =\min \left[\frac{97,5-96,06}{3 x 0,708}, \frac{96,06-95}{3 x 0,708}\right] \\
& =\min [0,67,0,499]=0,499
\end{aligned}
$$


Dilihat dari hasil nilai $\mathrm{Cp}(0,588)$ dan Cpk $(0,499)$ kurang dari 1 , hal ini menunjukan kapabilitas proses untuk memenuhi spesifikasi yang ditentukan rendah dan proses belum kompetitif.

\section{ANALISA DAN PEMBAHASAN}

Analisa perhitungan overal equipment effectiviness (OEE) di PT XYZ dilakukan untuk melihat tingkat efektivitas mesin filling di produksi bagian skincare selama bulan Maret - November 2017. Pengukuran overal equipment effectiviness (OEE) ini merupakan perkalian antara availability, performance efficiency dan rate of quality product.

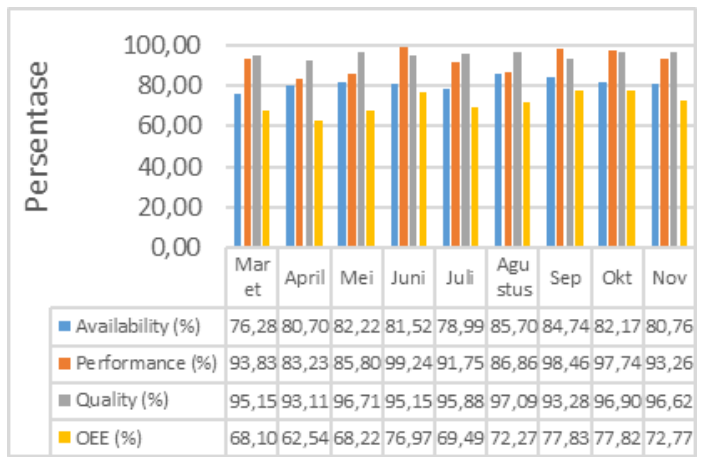

Gambar 3. Diagram Pengukuran Nilai OEE bulan Maret - November 2017

Dari diagram pengukuran nilai overal equipment effectiviness (OEE) di atas dapat disimpulkan antara lain:

1. Selama periode Maret- November 2017 di peroleh nilai OEE yang berkisar antara $(62,54 \%$ - 77,83\%), availability ratio berkisar ( 76,28 \% - 85,70\%), hasil performance efficiency yang berkisar $(83,23 \%-99,24 \%)$ dan rate quality product berkisar $(93,11 \%-97,09 \%)$.

2. Nilai OEE tertinggi pada bulan September sebesar $77,83 \%$. Dan nilai OEE terendah pada bulan April 2017 $(62,54 \%)$.

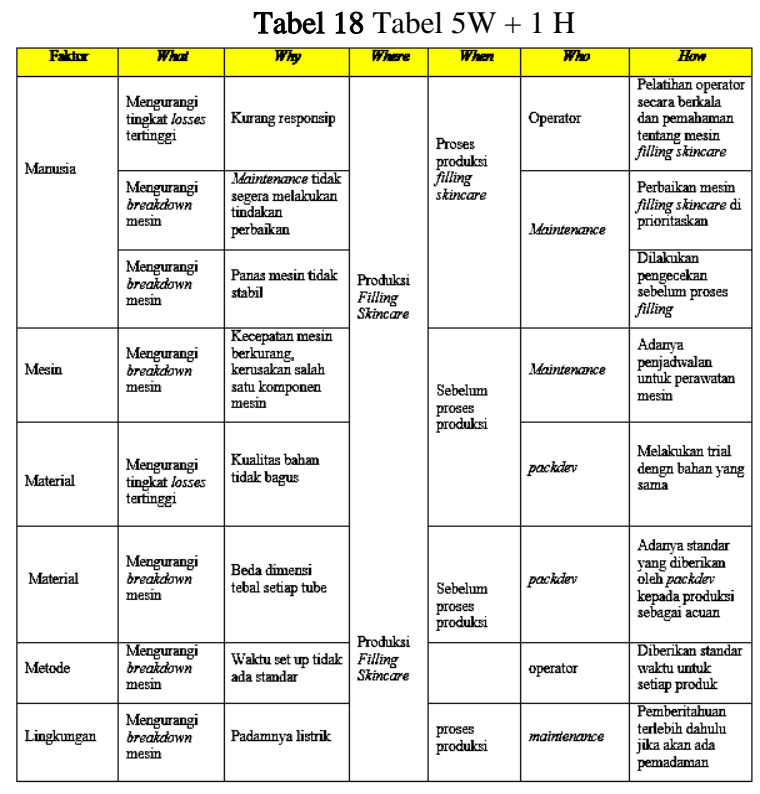

\section{KESIMPULAN DAN SARAN}

1. Kesimpulan

Berdasarkan hasil analisa dan pembahasan dari uraian pengukuran Overall equipment effectiviness (OEE) di mesin filling skincare di PT XYZ, dapat diambil beberapa kesimpulan yaitu:

1. Nilai Overall equipment effectiviness (OEE) yang terjadi selama bulan MaretNovember 2017 dapat kita lihat efektivitas mesin tidak memenuhi standar karena di bawah 85\%, sehingga pemeliharaan mesin harus ditingkatkan dan diperbaiki agar dapat mencapai zero defect sesuai dengan tujuan konsep TPM.

2. Faktor yang memiliki persentase terbesar dari faktor six big losses adalah reduce speed $(34,92 \%)$ dan breakdown losses $(32,08 \%)$.

\section{Saran}

Dari penelitian ini dapat diberikan beberapa saran agar perusahaan dapat memperbaiki pemeliharaan yang telah terlaksana, antara lain:

1. Hendaknya jadwal pemeliharaan mesin di perusahaan lebih dilaksanakan dengan baik agar dapat dihindarkan kerusakaan mendadak, sehingga waktu breakdown mesin tereliminasi.

2. Perusahaan perlu menanamkan kesadaran kepada seluruh karyawan untuk dapat ikut serta berperan aktif dalam pengingkatan produktivitas untuk perusahaan. 
3. Penggunaan material sesuai spesifikasi mesin.

\section{DAFTAR PUSTAKA}

Baroto, T. 2003. Pengantar Teknik Industri. Universitas Muhamamadiyah Malang: Malang.

Betrianis dan Robby Suhendra. 2005. Pengukuran nilai overall equipment Effectiveness sebagai dasar usaha perbaikan Proses manufaktur pada lini produksi (studi kasus pada stamping production division sebuah industri otomotif) Jurnal Teknik Industri Vol. 7, NO. 2, DESEMBER 2005: 91- 100.

Dani, D. 2012. Usulan Perbaikan Untuk Meningkatkan Efisiensi Produksi Mesin Fin Forming Dengan Menggunakan Metode Efektifitas Seluruh Peralatan (OEE) di PT. XYZ. Skripsi S1, Universitas Guna Darma: Jakarta.

Delia et al. 2014. Usulan Peningkatan Efektivitas Mesin Cetak Manual Menggunakan Metode Overall Equipment Effectiveness (OEE) (Studi Kasus Di Perusahaan Kerupuk TTN) Jurusan Teknik Industri Institut Teknologi Nasional (Itenas): Bandung. Tersedia pada:

Diandra et al.2016. Analisa Total Productive Maintenance Terhadap Produktivitas Kapal/Armada Menggunakan Metode Overall Equipment Effectiveness Pada Pt. Global Trans Energy International 9, No 1, February 2016.

Eka I'mal Maulana, TB. 2012. "Usulan Penerapan TPM dengan Menggunakan Metode OEE Untuk Meningkatkan Produktivitas Mesin Vapour Phase Drying Oven di PT. Unitec Indonesia. Institut Sains dan Teknologi Al-Kamal: Jakarta.
Ika, Dyah Rinawati dan Nadia Cynthia Dewi. 2014. Analisis Penerapan Total Productive Maintenance (Tpm) Menggunakan Overall Equipment Efectiveness (OEE) dan Six Big Losses Pada Mesin Cavitec di PT. Essentra surabaya. Program Studi Teknik Industri Fakultas Teknik, Universitas Diponegoro. Tersedia pada:

Iswardi dan M. Sayuti. 2016. Analisis Produktivitas Perawatan Mesin dengan Metode TPM pada mesin Mixing Section. Tersedia pada:

Karim, Achmad Jamaludin Abdul. 2016. Usulan Perbaikan Untuk Meningkatkan Efektifitas Mesin Pressing Race Gap Steering Dengan Menggunakan Oee (Overall Equipment Effectiveness) Pada Bagian Assemblingdi Pt.Suzuki Indomobil Motor. Jurusan teknik industri. Fakultas Teknik Universitas Muhammadiyah Jakarta.

Nakajima, S. 1988. Introduction to TPM. Cambridge: Productivity Press.

Ni made Sudri, Amalia mareti. 2012. Analisis Produktivitas menggunakan OEE pada PT XYZ. Vol.01 No.01, Januari-Maret 2012.

Nugroho, Asrofi. 2015. Usulan Perbaikan TPM dengan Perhitungan OEE Pada Mechine Wrapping Horizontal Di PT. $X Y Z$. Institut Sains dan Teknologi AlKamal: Jakarta.

Nursanti, Ida dan Yoko Susanto. 2014. Analisis Perhitungan Overall Equipment Effectiveness (Oee) Pada Mesin Packing Untuk Meningkatkan Nilai Availability Mesin Packing Untuk Meningkatkan Nilai Availability.

Septian et al.2012. Pengukuran nilai overall equipment effectiveness (oee) sebagai pedoman perbaikan efektivitas mesin $c n c$ cutting. Jurnal Teknik Pomits vol. 1, no. 1, (2012) 1-6. 